\title{
$45, X$ product of conception after preimplantation genetic diagnosis and euploid embryo transfer: evidence of a spontaneous conception confirmed by DNA fingerprinting
}

Daniela Bettio $^{1^{*}}$ (D) Antonio Capalbo ${ }^{2,3}$, Elena Albani ${ }^{4}$, Laura Rienzi ${ }^{2,3}$, Valentina Achille ${ }^{1}$, Anna Venci ${ }^{1}$, Filippo Maria Ubaldi ${ }^{2,3}$ and Paolo Emanuele Levi Setti ${ }^{4}$

\begin{abstract}
Background: Preimplantation genetic screening (PGS) provides an opportunity to eliminate a potential implantation failure due to aneuploidy in infertile couples. Some studies clearly show that twins following single embryo transfer (SET) can be the result of a concurrent natural conception and an incidence as high as 1 in 5 twins has been reported.

In our case PGS was performed on trophectoderm (TE) biopsies by quantitative polymerase chain reaction (qPCR). The product of conception (POC) was cytogenetically investigated after selection of the placental villi by means of the direct method. Molecular cytogenetic characterization of the POC was performed by fluorescence in situ hybridization (FISH) and array-comparative genomic hybridization (a-CGH) analyses. To investigate the possibility of a spontaneous conception, a panel of 40 single nucleotide polymorphisms (SNPs) was used to compare genetic similarity between the DNA of the POC and the DNA leftover of the TE biopsy.
\end{abstract}

Findings: We describe a 36-year old infertile woman undergoing PGS who had a spontaneous abortion after a single euploid embryo transfer on a spontaneous cycle. The POC showed a 45,X karyotype confirmed by FISH and a-CGH. DNA fingerprinting demonstrated a genetic similarity of $75 \%$ between the DNA of the POC and TE biopsy, consistent with a sibling status. All supernumerary euploid embryos were also tested showing a non-self relationship with the $\mathrm{POC}$, excluding a mix-up event at the time of fetal embryo transfer.

Conclusions: DNA fingerprinting of the transferred blastocyst and POC, confirmed the occurrence of a spontaneous conception. This case challenges the assumption that a pregnancy after assisted reproductive technology (ART) is always a result of ART, and strengthens the importance to avoid intercourses during PGS and natural transfer cycles. Moreover, cytogenetic analysis of the POCs is strongly recommended along with fingerprinting children born after PGS to see what the concordance is between the embryo transferred and the resultant child.

(Continued on next page)

\footnotetext{
* Correspondence: daniela.bettio@humanitas.it

${ }^{1}$ Cytogenetic and Medical Genetic Laboratory, Operative Unit of Clinical Investigations, Humanitas Clinical and Research Center, Via Manzoni 56, 20089 Rozzano, Milan, Italy

Full list of author information is available at the end of the article
} 
(Continued from previous page)

Keywords: POC, PGS, Blastocyst transfer, Cytogenetics, SNPs

Abbreviations: a-CGH, Array-comparative genomic hybridization; AMH, Anti-Müllerian hormone; ART, Assisted reproductive technology; FISH, Fluorescence in situ hybridization; FSH, Follicle-stimulating hormone; GnRH, Gonadotropin-releasing hormone; ICSI, Intracytoplasmic sperm injection; IUI, Intrauterine insemination; IVF, In vitro fertilization; LH, Luteinizing hormone; PGD, Preimplantation genetic diagnosis; PGS, Preimplantation genetic screening; POC, Product of conception; qPCR, Quantitative polymerase chain reaction; rFSH, Recombinant FSH; rhCG, Recombinant human chorionic gonadotropin; SET, Single embryo transfer; SNPs, Single nucleotide polymorphisms; TE, Trophectoderm

\section{Introduction}

PGS is an early method to detect aneuploidies in preimplantation embryos. PGS can be offered to patients with an increased risk of having a higher percentage of chromosomally abnormal embryos, improving the reproductive outcome. By transferring only chromosomally normal embryos the miscarriage rates are expected to be lower, since about $60-70 \%$ of miscarriages in the first trimester result from chromosomal abnormalities in the fetus [1].

Some studies clearly show that twins following SET can be the result of a concurrent natural conception [2,3] and an incidence as high as 1 in 5 twins has been reported [4].

We describe a rare case of a 36-year-old infertile patient with recurrent implantation failures. PGS was performed and an euploid blastocyst transferred. However, a spontaneous abortion occurred after 13 weeks of gestation, ascertained to be 10 at ultrasound examination. Cytogenetic analysis revealed a 45,X karyotype. DNA fingerprinting analysis of POC and the euploid embryo transferred excluded a self-relationship confirming the occurrence of a spontaneous conception in concomitance with SET.

\section{Materials and methods}

A 36-year old woman experiencing 6 years infertility with a diagnosis of severe endometriosis was referred to Humanitas Fertility Center. She had a miscarriage at 8 weeks after an intrauterine insemination (IUI), other 2 negative IUI cycles and 3 negative in vitro fertilization (IVF) cycles with the transfer of 11 cleavage stage embryos from fresh and frozen cycles performed in other centers. A normal uterine cavity was confirmed at hysteroscopy while a transvaginal ultrasound imaging showed a $18 \mathrm{~mm}$ small endometrial cyst of the right ovary and $12 \mathrm{~mm}$ recto-vaginal lesion. Despite a high follicle-stimulating hormone (FSH) level of $14 \mathrm{IU} / \mathrm{L}$, ovarian reserve assessed to be normal with an antiMüllerian hormone (AMH) level of $3.8 \mathrm{ng} / \mathrm{ml}$ and the existence of 10 antral follicles. Her partner sperm analysis showed 12 million total motile sperm with $2 \%$ normal forms and $80 \%$ vitality. After counseling and obtaining informed consent, the patient was enrolled for a first attempt intracytoplasmic sperm injection (ICSI) with PGS cycle. Controlled ovarian hyper-stimulation was started with 225 IU recombinant FSH ( $\mathrm{rFSH})$ in a gonadotropin-releasing hormone $(\mathrm{GnRH})$ antagonist analog cycle. Recombinant human chorionic gonadotropin (rhCG) (250 mcg) was administered on day 13 of the induction cycle after a total rFSH dose of 3325 IU.

A transvaginal ultrasound guided under deep sedation oocyte retrieval was performed $36 \mathrm{~h}$ after the rhCG trigger and 9 metaphase II oocytes were retrieved. In 8 metaphase II oocytes ICSI was performed and placed in an incubator with an integrated time-lapse system, where the embryos were cultured individually in $25 \mu \mathrm{l}$ microwells and monitored for $24 \mathrm{~h}$. At 16-18 h postICSI, the 8 oocytes were assessed for the presence of 2 pronuclei and cultured until blastocyst stage. Three expanded blastocysts underwent biopsy of TE cells day 5 and 4 day 6 as previously described [5], 1 embryo degenerated after development to morula. Blastocyst quality was assessed immediately before TE biopsy [6], and blastocysts vitrified according to the protocol described by Kuwayama et al. [7]. Of the 7 biopsied and cryopreserved blastocysts, 4 were euploid. TE biopsies were analysed by qPCR based comprehensive chromosome diagnosis [8, 9]. This method has been extensively validated for chromosome copy number analysis of TE biopsies in preclinical $[8,9]$ and clinical studies $[10,11]$ and was reported to have a recognizable error rate of $0.2 \%$ in clinical pregnancies [12].

The embryo transfer was scheduled on a spontaneous cycle. The patient was monitored from day 6 of the cycle by ultrasound and a urinary luteinizing hormone (LH) kit. On cycle day 15 an endometrial thickness of $12.2 \mathrm{~mm}$ with 2 follicles of 18 and $22 \mathrm{~mm}$ were observed with a positive LH determination. Seven days after LH surge a single euploid blastocyst (embryo number 3) was selected for transfer based on morphological score, warmed and cultured at $37{ }^{\circ} \mathrm{C}$ until transfer, performed under ultrasound guidance.

A positive $\mathrm{hCG}$ determination was performed 14 days after the embryo transfer (1765 IU) and a 6 weeks ultrasound showed an intrauterine gestation with an embryo with normal fetal heart rate. 
Table 1 Genotyping data of 40 SNPs in technical duplicates used to determine genetic similarity between the product of conception and euploid IVF embryos. 1 and 2 represents the two alleles for each SNP

\begin{tabular}{|c|c|c|c|c|}
\hline Assay ID & Villi gDNA & Embryo 3 & Embryo 6 & Embryo 7 \\
\hline Assay01 & 11 & 11 & 22 & 11 \\
\hline Assay01 & 11 & 11 & 22 & 11 \\
\hline Assay02 & 22 & unamplified & 22 & 22 \\
\hline Assay02 & 22 & unamplified & 22 & 22 \\
\hline Assay03 & 11 & 11 & 11 & 11 \\
\hline Assay03 & 11 & 11 & 11 & 11 \\
\hline Assay04 & 11 & 11 & 11 & 12 \\
\hline Assay04 & 11 & 11 & 11 & 12 \\
\hline Assay05 & 12 & 22 & 12 & 12 \\
\hline Assay05 & 12 & 22 & 12 & 12 \\
\hline Assay06 & 22 & 22 & 12 & 22 \\
\hline Assay06 & 22 & 22 & 12 & 22 \\
\hline Assay07 & 12 & 11 & 11 & 12 \\
\hline Assay07 & 12 & 11 & 11 & 12 \\
\hline Assay08 & 22 & 22 & 22 & 22 \\
\hline Assay08 & 22 & 22 & 22 & 22 \\
\hline Assay09 & 12 & unamplified & 12 & 12 \\
\hline Assay09 & 12 & unamplified & 12 & 12 \\
\hline Assay 10 & 12 & 11 & 11 & 11 \\
\hline Assay 10 & 12 & 11 & 11 & 11 \\
\hline Assay11 & 11 & 12 & 12 & 11 \\
\hline Assay 11 & 11 & 12 & 12 & 11 \\
\hline Assay 12 & 12 & 12 & 12 & 12 \\
\hline Assay 12 & 12 & 12 & 12 & 12 \\
\hline Assay13 & 11 & 11 & 11 & 11 \\
\hline Assay13 & 11 & 11 & 11 & 11 \\
\hline Assay 14 & 22 & 11 & 22 & 12 \\
\hline Assay14 & 22 & 11 & 22 & 12 \\
\hline Assay15 & 22 & 22 & 12 & 12 \\
\hline Assay15 & 22 & 22 & 12 & 12 \\
\hline Assay 16 & 12 & 12 & 11 & 22 \\
\hline Assay 16 & 12 & 12 & 11 & 22 \\
\hline Assay 17 & 12 & 12 & 11 & 12 \\
\hline Assay 17 & 12 & 12 & 11 & 12 \\
\hline Assay 18 & 12 & 12 & 12 & 12 \\
\hline Assay18 & 12 & 12 & 12 & 12 \\
\hline Assay19 & 12 & 12 & 22 & 12 \\
\hline Assay19 & 12 & 12 & 22 & 12 \\
\hline Assay20 & 11 & 11 & 11 & 11 \\
\hline Assay20 & 11 & 11 & 11 & 11 \\
\hline
\end{tabular}

Table 1 Genotyping data of 40 SNPs in technical duplicates used to determine genetic similarity between the product of conception and euploid IVF embryos. 1 and 2 represents the two alleles for each SNP (Continued)

\begin{tabular}{|c|c|c|c|c|}
\hline Assay21 & 12 & 12 & 22 & 12 \\
\hline Assay21 & 12 & 12 & 22 & 12 \\
\hline Assay 22 & 22 & 22 & 12 & 22 \\
\hline Assay22 & 22 & 22 & 12 & 22 \\
\hline Assay23 & 11 & 12 & 12 & 12 \\
\hline Assay23 & 11 & 12 & 12 & 12 \\
\hline Assay24 & 22 & 22 & 12 & 12 \\
\hline Assay24 & 22 & 22 & 12 & 12 \\
\hline Assay 25 & 12 & 12 & 12 & 12 \\
\hline Assay 25 & 12 & 12 & 12 & 12 \\
\hline Assay26 & 22 & 22 & 12 & 22 \\
\hline Assay 26 & 22 & 22 & 12 & 22 \\
\hline Assay27 & 22 & 12 & 22 & 12 \\
\hline Assay27 & 22 & 12 & 22 & 12 \\
\hline Assay28 & 12 & 12 & 12 & 12 \\
\hline Assay28 & 12 & 12 & 12 & 12 \\
\hline Assay29 & 11 & 12 & 11 & 11 \\
\hline Assay29 & 11 & 12 & 11 & 11 \\
\hline Assay30 & 12 & 12 & 12 & 12 \\
\hline Assay30 & 12 & 12 & 12 & 12 \\
\hline Assay31 & 12 & 12 & 22 & 12 \\
\hline Assay31 & 12 & 12 & 22 & 12 \\
\hline Assay32 & 22 & 22 & 22 & 22 \\
\hline Assay32 & 22 & 22 & 22 & 22 \\
\hline Assay33 & 11 & 11 & 12 & 11 \\
\hline Assay33 & 11 & 11 & 12 & 11 \\
\hline Assay34 & 22 & 22 & 22 & 12 \\
\hline Assay34 & 22 & 22 & 22 & 12 \\
\hline Assay35 & 22 & 22 & 22 & 22 \\
\hline Assay35 & 22 & 22 & 22 & 22 \\
\hline Assay36 & 11 & 11 & 11 & 11 \\
\hline Assay36 & 11 & 11 & 11 & 11 \\
\hline Assay37 & 12 & 11 & 11 & 11 \\
\hline Assay37 & 12 & 11 & 11 & 11 \\
\hline Assay38 & 12 & 12 & 12 & 12 \\
\hline Assay38 & 12 & 12 & 12 & 12 \\
\hline Assay39 & 11 & 12 & 11 & 11 \\
\hline Assay39 & 11 & 12 & 11 & 11 \\
\hline Assay40 & 11 & 11 & 12 & 11 \\
\hline Assay40 & 11 & 11 & 12 & 11 \\
\hline
\end{tabular}


A diagnosis of internal abortion was performed at 13 weeks with a 10 weeks embryo development and after the diagnosis the patients was submitted to aspiration and curettage with selection of villous materials immediately sent to our Cytogenetic Laboratory.

Placental villi were then further selected under the inverted microscope and cytogenetic analysis performed by direct preparation after $24 \mathrm{~h}$ incubation [13]. This is the method of choice in our laboratory because it avoids the growth of normal cells from possible endometrial contamination [1]. Parental karyotyping was performed according to standard procedures.

FISH on 1000 interphase nuclei using Vysis CEPX (DXZ1) Spectrum Green Probe (Abbott Molecular, Abbott Park, Illinois, US), specific for chromosome X centromere was conducted following the manufacturer's recommendations.

Array-CGH study was performed on the DNA extracted from uncultured villi using the QIAamp Mini Kit (QIAGEN ${ }^{\circ}$, Hilden, Germany) and hybridized to the SurePrint G3 Cancer CGH + SNP $4 \times 180 \mathrm{~K}$ microarray platform (Agilent Technologies, Santa Clara, CA, USA). Data were analysed with Agilent CytoGenomics 3.0.1.1 software.

Since the couple did not abstain from having sexual intercourses during the embryo transfer period, DNA fingerprinting analysis of excess embryonic and POC DNA was carried out to rule out the hypothesis of a spontaneous conception rather than a false PGS negative result. A set of 40 previously published SNPs with high heterozygosity and low allele frequency variation were utilized [14]. These SNPs were originally characterized against $\sim 2070$ individuals from 40 populations. The estimated probability that siblings will have identical genotypes is 0.5 raised to the power of the number of SNPs used, since all of these markers have alleles close to 50:50 in the population. This technique has been validated by Scott and colleagues [15] as the first seamless and inexpensive trophectoderm qPCR-based DNA fingerprinting technology allowing the unequivocal discrimination of sibling human embryos and foetuses. Briefly, for either the multiplex amplification PCR product residual from the TE biopsy or the purified genomic DNA of the POC, real-time PCR for allelic discrimination was performed in duplicate reactions for each of the individual 40 loci. Each reaction used the individual TaqMan SNP Genotyping Assays, TaqMan Genotyping Master Mix (Applied Biosystems Inc.), a $5 \mu$ l reaction volume, a 384-well plate, and a Quant Studio sequence detection system, as recommended by the supplier (Applied Biosystems Inc.). Informative SNP genotypes were compared between samples to determine the levels of similarity and standard deviations from the mean were calculated.

\section{Results and discussion}

The couple's karyotype was normal. Cytogenetic analysis on 20 Q-banded metaphases obtained from the POC showed a 45,X karyotype. This result was confirmed by FISH analysis showing one signal for CEPX in $94.9 \%$ of the nuclei. In $5.1 \%$ of nuclei 2 signals were present, probably due to a small maternal cell contamination that is difficult to avoid in a POC sample even after placenta villi selection. The 45 , $\mathrm{X}$ karyotype observed in the metaphases obtained after $24 \mathrm{~h}$ of incubation excluded a mosaic karyotype in the embryo.

Array-CGH analysis performed on DNA from uncultured villi confirmed chromosome $\mathrm{X}$ monosomy.

Allelic discrimination analysis of 40 SNPs of the excess DNA from all the euploid blastocysts produced during the present IVF cycle, revealed that none of them had a genotype consistent with the POC. In particular, locus dropout (no amplification of either allele) was observed in only 4 assays of embryo number 3 , with an overall call rate of $97.5 \%(156 / 160)$ (Table 1). All the euploid embryos showed a similarity rate to POC below $80 \%$, clearly consistent with a sibling genotype and a non-selfrelationship (Table 2). This analysis confirmed the hypothesis of a spontaneous conception in the course of the natural frozen embryo transfer cycle.

To our knowledge this the only case of PGS and euploid SET resulted in a 45,X POC as consequence of a natural pregnancy. A similar event has been reported in a large study about twin births after SET where the authors demonstrated that about 1 in 5 twins is due to a concurrent spontaneous conception [4]. Another report described a case of dizygotic twins of different-sex delivered after SET demonstrated to be the consequence of a natural fertilization [2].

\section{Conclusions}

Our case report demonstrates the occurrence of an aneuploid spontaneous conception, resulted in a miscarriage, in the course of a natural SET cycle. This case highlights the importance of avoiding intercourses and natural transfer cycles for couples with reproductive genetic risk, such as those undergoing preimplantation genetic diagnosis (PGD)/PGS cycles, in order not only to reduce the incidence of multiple pregnancies but especially to avoid the risk of aneuploid natural conceptions.

Table 2 Genetic similarity of the 3 euploid embryos obtained during the IVF cycle with the genomic DNA from the aneuploid POC

\begin{tabular}{ll}
\hline Sample ID & Similarity to POC gDNA \\
\hline Embryo 3 & $74 \%$ \\
Embryo 6 & $55 \%$ \\
Embryo 7 & $75 \%$ \\
\hline
\end{tabular}


Moreover, cytogenetic analysis of the POCs and fingerprinting of the children born after PGS are strongly recommended.

Furthermore, with this study we confirm that parental DNA information is not necessary since discrimination was achieved based on a clear genotypic heterogeneity among samples, without incorporating selection of informative SNPs from parental genotype. Therefore, the additional time and expense of evaluating parental DNA could be avoided with this methodology as also previously reported [15].

\section{Acknowledgements}

The authors thank Ms. Luciana Di Schiena for the technical assistance.

\section{Funding}

No funding to declare.

\section{Availability of data and materials}

Not applicable.

\section{Authors' contributions}

PELS is the head of the Fertility Center who personally managed and counselled the patients. EA is the embryologist who managed the ICSI laboratory procedures. $\mathrm{DB}, \mathrm{VA}$ and $\mathrm{AV}$ are the cytogeneticists who performed the karyotype, FISH and a-CGH analyses. AC, LR and FMU are the molecular biologists who managed PGS and DNA fingerprinting analysis. DB and AC were involved in the study design, DB in supervision and paper drafting. All authors read and approved the final manuscript.

\section{Competing interests}

The authors declare that they have no competing interests.

\section{Consent for publication}

Written informed consent for publication of the clinical details and/or clinical images was obtained from the patient. A copy of the consent form is available for review by the Editor of this journal.

\section{Ethics approval and consent to participate}

Ethics approval not needed.

The patient signed our institutional consent for genetic analyses, and gave the consent to use the clinical data.

\section{Author details}

${ }^{1}$ Cytogenetic and Medical Genetic Laboratory, Operative Unit of Clinical Investigations, Humanitas Clinical and Research Center, Via Manzoni 56, 20089 Rozzano, Milan, Italy. ${ }^{2}$ GENERA, Reproductive Medicine Centers, Rome, Italy. ${ }^{3}$ GENETYX, Molecular Genetics Laboratory, Via Fermi 1, Marostica, Vicenza, Italy. ${ }^{4}$ Department of Gynecology, Division of Gynecology and Reproductive Medicine, Fertility Center, Humanitas Clinical and Research Center, Via Manzoni 56, Rozzano, Milan, Italy.

Received: 1 July 2016 Accepted: 25 August 2016

Published online: 06 September 2016

\section{References}

1. Bettio D, Venci A, Levi Setti PE. Chromosomal abnormalities in miscarriages after different assisted reproduction procedures. Placenta. 2008;29(Suppl B):126-8.

2. Kyono K, Nakajo Y, Nishinaka C, Araki Y, Doshida M, Toya M, Kanto S. A birth of twins-one boy and one girl-from a single embryo transfer and a possible natural pregnancy. J Assist Reprod Genet. 2009;26:553-4.

3. Van der Hoorn ML, Helmerhorst F, Claas F, Scherjon S. Dizygotic twin pregnancy after transfer of one embryo. Fertil Steril. 2011;95:805.e1-3.

4. Osianlis T, Rombauts L, Gabbe M, Motteram C, Vollenhoven V. Incidence and zygosity of twin births following transfers using a single fresh or frozen embryo. Hum Reprod. 2014;29:1438-43.

5. Capalbo A, Rienzi L, Cimadomo D, Maggiulli R, Elliott T, Wright G, Nagy ZP, Ubaldi FM. Correlation between standard blastocyst morphology, euploidy and implantation: an observational study in two centers involving 956 screened blastocysts. Hum Reprod. 2014:29:1173-81.

6. Alpha Scientists in Reproductive Medicine and ESHRE Special Interest Group of Embryology. Collaborators, Balaban B, Brison D, Calderón G, Catt J, Conaghan J, Cowan L, Ebner T, Gardner D, Hardarson T, Lundin K, Cristina Magli M, Mortimer D, Mortimer S, Munné S, Royere D, Scott L, Smitz J, Thornhill A, van Blerkom J, Van den Abbeel E. The Istanbul consensus workshop on embryo assessment: proceedings of an expert meeting. Hum Reprod. 2011:26:1270-83.

7. Kuwayama M, Vajta G, leda S, Kato O. Comparison of open and closed methods for vitrification of human embryos and the elimination of potential contamination. Reprod Biomed Online. 2005;115:608-14.

8. Treff NR, Tao X, Ferry KM, Su J, Taylor D, Scott Jr RT. Development and validation of an accurate quantitative real-time polymerase chain reaction-based assay for human blastocyst comprehensive chromosomal aneuploidy screening. Fertil Steril. 2012;97:819-24.

9. Capalbo A, Treff NR, Cimadomo D, Tao X, Upham K, Ubaldi FM, Rienzi L, Scott Jr RT. Comparison of array comparative genomic hybridization and quantitative real-time PCR-based aneuploidy screening of blastocyst biopsies. Eur J Hum Genet. 2015;23:901-6.

10. Forman EJ, Hong KH, Ferry KM, Tao X, Taylor D, Levy B, Treff NR, Scott Jr RT. In vitro fertilization with single euploid blastocyst transfer: a randomized controlled trial. Fertil Steril. 2013;100:100-7.

11. Scott Jr RT, Upham KM, Forman EJ, Hong KH, Scott KL, Taylor D, Tao X, Tre NR. Blastocyst biopsy with comprehensive chromosome screening and fresh embryo transfer significantly increases in vitro fertilization implantation and delivery rates: a randomized controlled trial. Fertil Steril. 2013;100:697-703.

12. Werner MD, Leondires MP, Schoolcraft WB, Miller BT, Copperman AB, Robins ED, Arredondo F, Hickman TN, Gutmann J, Schillings WJ, Levy B, Taylor D, Treff NR, Scott Jr RT. Clinically recognizable error rate after the transfer of comprehensive chromosomal screened euploid embryos is low. Fertil Steril. 2014;102:1613-8.

13. Simoni G, Brambati B, Danesino C, Rossella F, Terzoli GL, Ferrari M, Fraccaro M. Efficient direct chromosome analyses and enzyme determinations from chorionic villi samples in the first trimester of pregnancy. Hum Genet. 1983;64:349-57.

14. Pakstis AJ, Speed WC, Kidd JR, Kidd KK. Candidate SNPs for a universal individual identification panel. Hum Genet. 2007;121:305-17.

15. Scott 3rd RT, Su J, Tao X, Forman EJ, Hong KH, Taylor D, Treff NR, Trophectoderm DNA fingerprinting by quantitative real-time PCR successfully distinguishes sibling human embryos. J Assist Reprod Genet. 2014:31:1421-5.

Submit your next manuscript to BioMed Central and we will help you at every step:

- We accept pre-submission inquiries

- Our selector tool helps you to find the most relevant journal

- We provide round the clock customer support

- Convenient online submission

- Thorough peer review

- Inclusion in PubMed and all major indexing services

- Maximum visibility for your research

Submit your manuscript at www.biomedcentral.com/submit
Biomed Central 